\title{
Cerebral epithelioid hemangioendothelioma with thoracic simultaneous involvement: advanced MRI features
}

\author{
Hemangioendotelioma epitelioide cerebral com envolvimento torácico simultâneo: \\ achados nas técnicas não convencionais de ressonância magnética
}

Paulo Cesar Rocha Oliveira', Fábio Peixoto Alcantara1, Pedro Erthal de Souza-Vianna', Andreia Portilho de Brito²
'Diagnostic Imaging Department, SARAH Hospital-Brasilia Center, SARAH Network of Rehabilitation Hospitals, Brasília DF, Brazil;
${ }^{2}$ Surgical Pathology Laboratory, SARAH Hospital-Brasilia Center, SARAH Network of Rehabilitation Hospitals, Brasília DF, Brazil.

Correspondence: Paulo Cesar Rocha Oliveira; Diagnostic Imaging Department, Hospital SARAH-Brasília, SARAH Network of Rehabilitation Hospitals, SMHS Q 501 / BL A; 70335-901 Brasília DF - Brasil; E-mail: bsbpaulocesar@gmail.com

Conflict of interest: There is no conflict of interest to declare.

Received 13 December 2011; Received in final form 17 March 2012; Accepted 27 March 2012

Epithelioid hemangioendothelioma (EH) is a vascular neoplasm with epithelioid appearance and intermediate malignancy that can affect soft tissues, lungs, liver, bones, head and neck, vessels and intracranial structures, among other sites $^{1-3}$. Cerebral involvement is very rare $(<0.02 \%$ of all brain tumors) $)^{1}$. This latter can occur singly or in a multicentric context, and also as intracranial metastasis ${ }^{2,3}$. We present a case of a 37-year-old woman with a cerebral EH with thoracic involvement, emphasizing advanced MRI features.

\section{CASE}

In April 2010, a 37-year-old woman presented history of right-sided paresthesia for three years. Physical examination showed slight right hemiparesis. CSF analysis and blood tests were normal. MRI and CT revealed a solid and vascularized nodule in the left paracentral lobule measuring $1.8 \mathrm{~cm}$, with small foci of calcifications and facilitated diffusion (Fig 1A-D). MR spectroscopy demonstrated reduction of all peaks with Cho/NAA ratio of 0.50 (Fig 1E). Perfusion MRI showed a linear area of very high $\mathrm{rCBV}$, suggesting a vessel (Fig 1F). The remaining portions had rCBV values less than 1.5 times the corresponding contralateral normal-appearing white matter. Chest CT revealed multiple calcified and non-calcified pulmonary nodules. Abdominal CT was normal.

In August 2010, the brain tumor was resected in two parts, since a callosal marginal branch of anterior cerebral artery crossed it. The tumor was circumscribed, with no brain reaction (Fig 2A). Histologically, it was composed of short cords and small nests of rounded or polygonal cells in a loose "chondroid" matrix, with abundant eosinophilic cytoplasm (Fig 2B). Endothelial differentiation was seen
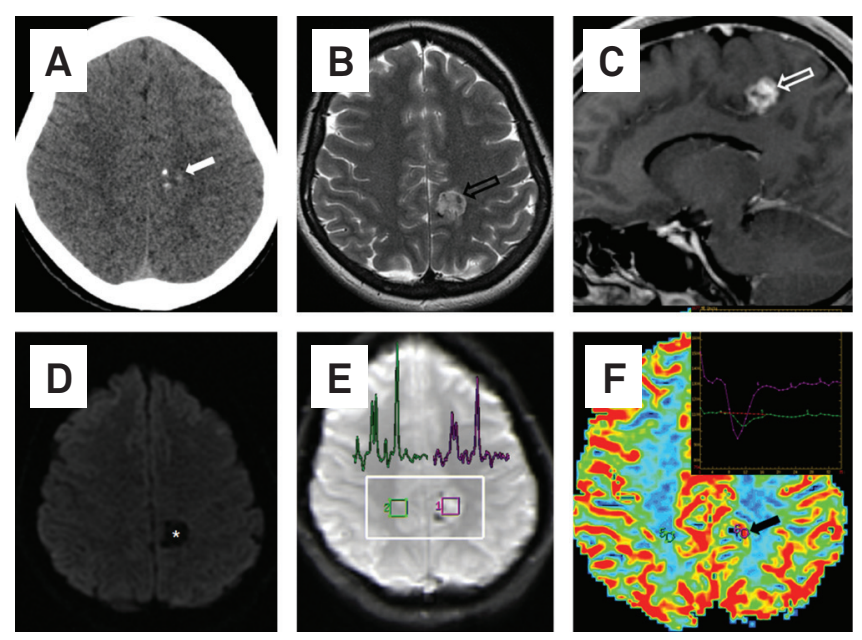

Fig 1. (A) Axial unenhanced CT image showing an ill-defined partially calcified nodule in the left paracentral lobule (solid white arrow). (B and C) Conventional MRI reveals a nodule with hyperintense signal on T2WI (open black arrow) and strong post-contrast enhancement (open white arrow). (D) Axial DWI (b-factor: $1,000 \mathrm{~mm} / \mathrm{s}^{2}$ ) demonstrates facilitated diffusion inside lesion (asterisk). (E) Axial parametric image with superimposed MR spectroscopy curves (PRESS, TE=144 ms) show low concentration of all metabolites within the lesion (pink). (F) A color-coded rCBV map and its respective time-signal intensity curves superimposed (top right) display a "hot" tubular intralesional area, consistent with a vessel (solid black arrow, pink curve).

as intracytoplasmic lumina in paraffin sections and by ultrastructural analysis. By immunohistochemistry, there was diffuse positivity for CD34 in these cells (Fig 2C). These findings were consistent with EH. One month later, a left thoracotomy revealed multiple nodules in the lung, pleura, and diaphragm. Some nodules were excised, displaying histopathologic features of EH. Thoracic disease was not responsive to sunitinib, but remains stable. In October 2011, she complained only of a slight right lower limb paresis. 

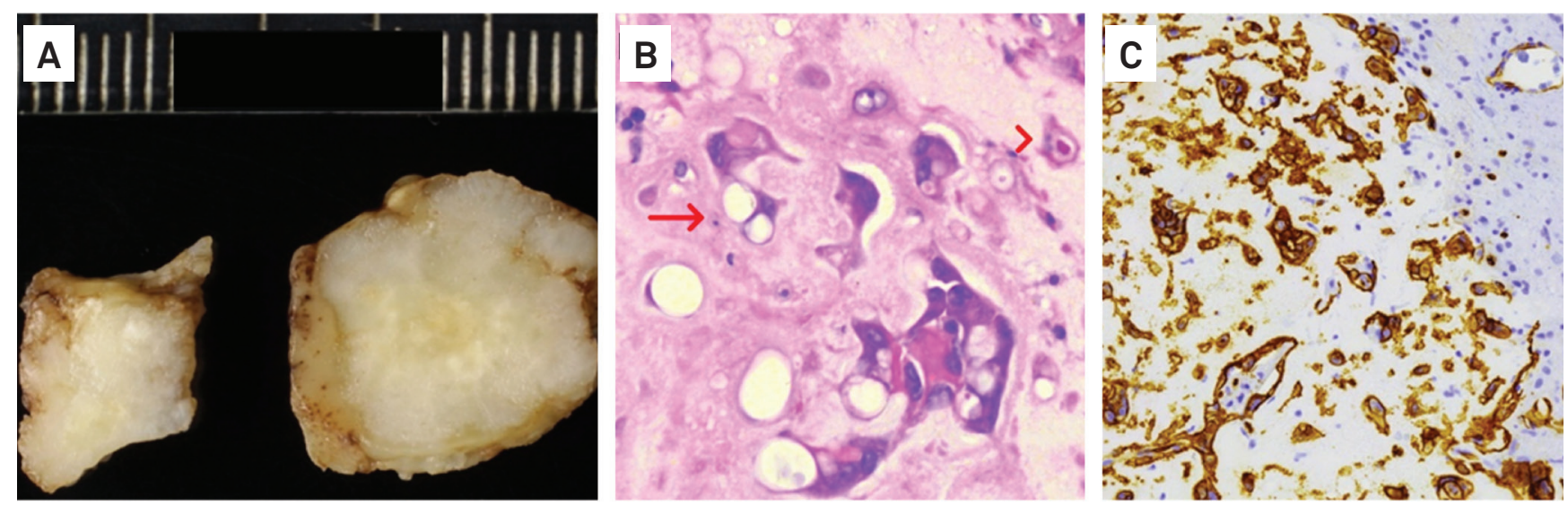

Fig 2. (A) Gross specimen: a cerebral circumscribed lesion. (B) Epithelioid hemangioendothelioma. Note eosinophilic epithelioid cells, in chondroid matrix, with intracytoplasmic lumen (arrow) sometimes containing a red cell (arrowhead).

(C) Immunohistochemistry: diffuse positivity for CD34 in the tumor cells (QBEND/10).

\section{DISCUSSION}

The differential diagnosis of cerebral EH includes cavernous hemangioma, angiosarcoma, hemangiopericytoma, hemangioblastoma, myxoid chondrosarcoma, chordoma, chordoid meningioma, glioma, and metastatic carcinomas ${ }^{1,3}$. Conventional MRI findings of cerebral EH are non specific, including solid appearance with intermediate, hypointense or heterogeneous signal on T1WI, hyperintense or heterogeneous signal on T2WI, diffuse and strong post-contrast enhancement, with or without marked peripheral hyposignal on $\mathrm{T} 2^{1-4}$. Solid-cystic variant also has been reported ${ }^{3,4}$.

From the best of our knowledge, DWI, MR spectroscopy and perfusion MRI features of intracranial EH have not been previously reported. In present case diffusion was facilitated, reflecting its hypocellular nature. MR spectroscopy showed reduced creatine, choline, and "NAA" intralesional peaks. Since EH is a non-neuronal tumor, a NAA peak is unexpected and could be related to partial volume effect. A remote alternative explanation could be a NAA-like peak ${ }^{5}$. On perfusion MRI EH showed no signs of neoangiogenesis, with a linear area of high rCBV interpreted as the intralesional vessel, in accordance with surgical and histopathologic findings.

The discovery of a cerebral EH mandates a search for involvement of other regions, particularly thorax and abdomen ${ }^{1}$. Surgical excision is the preferred treatment for cerebral EH ${ }^{3}$. Radiotherapy and $\alpha$-interferon have been used when the tumor is partially resected or unresectable ${ }^{1}$.

\section{References}

1. Yeo SK, Kim JH, Kim CJ, Lee JK. Intracranial epithelioid hemangioendothelioma. J Korean Neurosurg Soc 2007;42:129-131.

2. Endo T, Su CC, Numagami Y, Shirane R. Malignant intracranial epithelioid hemangioendothelioma presumably originating from the lung: case report. J Neurooncol 2004;67:337-343.

3. Hamlat A, Casallo-Quilliano C, Saikali S, Lesimple T, Brassier G. Epithelioid hemangioendothelioma of the infundibular-hypothalamic region: case report and literature review.J Neurooncol 2004;67:361-366.
4. Chan YL, Ng HK, Poon WS, Cheung HS. Epithelioid haemangioendothelioma of the brain: a case report. Neuroradiology 2001;43:848-850.

5. Liu X, Germin BI, Zhong J, Ekholm S. N-Acetyl peak in MR spectra of intracranial metastatic mucinous adenocarcinomas. Magn Reson Imaging 2010;28:1390-1394. 